
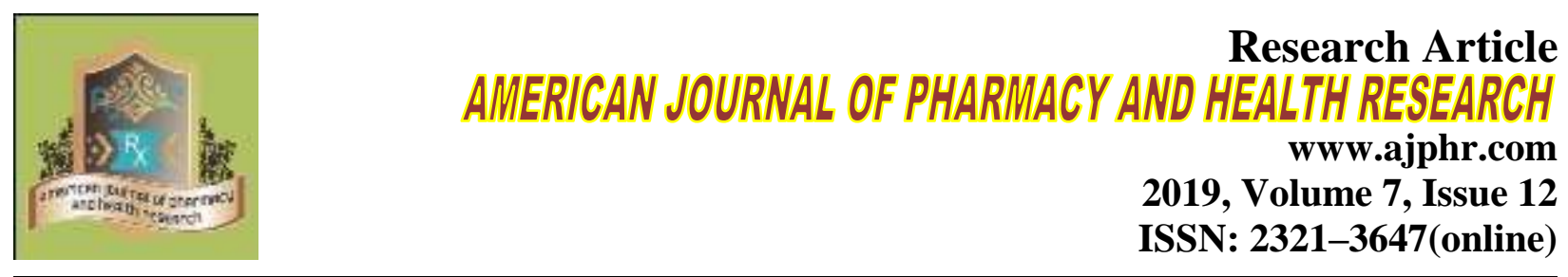

\title{
Evaluation of Anti-Hyperlipidemic Activity of Extracted Alpha- Linlenic Acid from natural Linum usitatissimum compared with Atorvastatin in high fat diet induced Rats.
}

\author{
Yerram Mounika*1, Ramavath Mohanbabu Naik ${ }^{2}$ \\ 1.Department of Pharmacology, Surabhi Dayakar Rao college of Pharmacy, Gajwel \\ (mandal), Siddipet(district), Telangana-502312. \\ 2.Department of Pharmaceutical Analysis and Quality Assurance, Gland institute of \\ pharmaceutical science, Kothapet(v), Near Narsapur, Medak(district),Telangana-502334.
}

\begin{abstract}
Linum Usitatissimum (LU) has a lipid-lowering action in both normal and diabetic animals. Because OS leaves are rich in oil, the present study was conducted to explain the antihyperlipidemic and organ-protective effect of LU fixed oil in rats fed with a high fat (HF) diet. LU fixed oil was extracted by hexane and the fatty acids composition identified by GC-MS. Four groups of male Wistar rats included a normal control group, a high fat fed-diet (HF) group, a HF group treated with LU fixed oil, and a HF group treated with a reference drug Atorvastatin. The results show that LU fixed oil contains five kinds of fatty acids, of which alpha-linolenic acid was the major fatty acid. LU fixed oil depressed high serum levels of total cholesterol, triglyceride, LDL-C, and AI, whereas no significant effect on HDL-C was observed. LU fixed oil also suppressed high levels of liver cholesterol and triglyceride with no significant effect on both lipids in feces. In addition, LU fixed oil normalized the high serum levels of LDH and CK-MB but no significant effect on high serum levels of ALT, AST, and ALP was obtained. We conclude that treatment with LU fixed oil during the last three weeks of HF diet feeding decreased the high serum lipid profile and expressed antiartherogenic and cardioprotective actions against hyperlipidemia. The anti-hyperlipidemic action of OS fixed oil was mainly resulted from the suppression of liver lipid synthesis. Linolenic acid and linoleic acid contained in LU fixed oil were possibly responsible for both lipid-lowering and cardiac protective action against hyperlipidemia.
\end{abstract}

Keywords: Anti-Hyperlipidemic Activity, Linum Usitatissimum, Linolenic Acid, Atorvastatin. 


\section{INTRODUCTION}

Hyperlipidemia is an excess of fatty substances called lipids, largely cholesterol and triglycerides, in the blood. It is also called hypolipoproteinemia because these fatty substances travel in the blood attached to proteins. This is the only way that these fatty substances can remain dissolved while in circulation.

Hyperlipidemia disease has afflicted humankind since antiquity. The treasure house of plant kingdom has a number of plants to treat this ailment. The indigenous system of medicine provides an abundant data about plants available for treatment of hyperlipidemia. A lot of work has been carried out by researches on various plants to evident their effectiveness in hyperlidemia. But still lots many are left which are used in the indigenous system but no systematic studies regarding their pharmacology have been carried out. One such natural medicine in indigenous system of medicine claimed to be useful in treatment of high fat deposition in various organs. Alpha-linolenic acid is natural medicine extracts from capsicum and other pepper plants the systematic pharmacological study is carried out to support its hyperlipidemic activity. Current study is under taken to evaluate weather the Alpha-linolenic acid possess anti-oxidant and anti hyperlipidemic activity and able to increase liver protection. So the purpose of present study is to evaluate effect of Alpha-linolenic acid on hyperlipidemia. Here the parameters included are

- Oxidative stress in liver.

- Serum cholesterol and HDL cholesterol and Total protein levels.

- Histopathology of liver and carotid artery in rats.

\section{MATERIALS AND METHOD}

\section{Animal husbandry}

All experiments and protocols described in present study were approved by the Institutional Animal Ethical Committee (IAEC) of S.V. University, Tirupathi and with permission from Committee for the purpose of Control and Supervision of Experiments on Animals (CPCSEA), Ministry of Social Justice and Empowerment, Government of India.

\section{Animals:}

Female Wister rats $(100 \pm 25)$ were housed in group of 6 animals and maintained under standardized condition (12-hours light/dark cycle, $24^{\circ} \mathrm{C}$ ) and fed with high fat diet food and purified drinking water ad libitum.

\section{Chemicals:}


Alpha-linolenic acid (sigma),

Epinephrine, DTNB (sigma),

Thiobarbituric acid (TBA) and Tri chloro acetic acid,

Hydrogen peroxide (SD fine chemicals Ltd).

Sodium dihydrogen phosphate, potassium dihydrogen phosphate, Tris buffer,

all other reagents used were of analytical grade

\section{Instrumentation:}

UV spectra were recorded in Cyber Spec UV-Visible spectrophotometer

\section{Experimental design:}

The experiment conducted for 45 days.

Wister rats $(\mathrm{n}=24)$ are divided in to 4groups as per following.

Group 1: (Normal) Received normal diet.

Group 2: high fat diet (egg white, vegetable fat, cakes, potatoes, cholesterol) and drinking tap water.

Group 3: $0.20 \%$ Alpha-linolenic acid + high fat diet treated.

Group 4:0.05mg Atrovastatin + high fat diet

Bio-Chemical studies: Parameters measured

\section{Serum analytical methods}

1.Estimation of total cholesterol

2.Estimation of HDL cholesterol

Tissue (liver) bio chemical methods

- Antioxidant and pro-oxidant enzymes

- Super oxide dismutase (SOD)( by the method Misra, Fridovichi L. et al., 1972).

- Catalase (Colowick et al., 1984).

- Glutathione (GSH) ( by the method Moran M.S et al., 1984).

- Malondialdehyde (MDA) ( by the method Slater T.F and Sawyer B.C et al., 1971).

\section{Physical methods}

Body weight

* Histopathology

- Liver

$\checkmark \quad$ Carotid artery 


\section{Bio chemical Studies:}

Serum Analytical Methods:

Estimation of Total cholesterol-MR:

(Chod-Pod/ Phosphotungstate Method)

Principle:

Cholesterol $+\mathrm{H}_{2} \mathrm{O}^{\mathrm{CHE}} \longrightarrow$ Cholesterol + free fatty acid

Cholesterol $+\mathrm{O}_{2}{ }_{2} \mathrm{CHOD} \quad$ cholest-4ene 3-one $+\mathrm{H}_{2} \mathrm{O}_{2}$

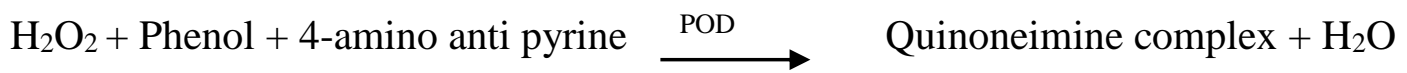

\section{Procedure:}

Pipette into 3 test tubes labeled Blank(B), Standard(S), and Total cholesterol( $\left.\mathrm{T}_{\mathrm{c}}\right)$ as shown below(Table 1).

Mix well and incubate for $5 \mathrm{~min}$ at $37^{\circ} \mathrm{C}$ or $10 \mathrm{~min}$ at R.T. Read the absorbance of standard(S),

Total cholesterol $\left(\mathrm{T}_{\mathrm{c}}\right)$ against blank at $505 \mathrm{~nm}$ or with green filter(500-540nm)

Calculations:

Table 1 Estimation of Total cholesterol-MR:

\begin{tabular}{lllllll}
\hline Reagent & \multicolumn{3}{c}{$\mathbf{1 . 0 m l}$ procedure } & \multicolumn{3}{c}{ 3.0 ml procedure } \\
& $\mathbf{B}$ & $\mathbf{S}$ & $\mathbf{T}_{\mathbf{c}}$ & $\mathbf{B}$ & $\mathbf{S}$ & $\mathbf{T}_{\mathbf{c}}$ \\
\hline Cholesterol reagent (1) & $1.0 \mathrm{ml}$ & $1.0 \mathrm{ml}$ & $1.0 \mathrm{ml}$ & $1.0 \mathrm{ml}$ & $1.0 \mathrm{ml}$ & $1.0 \mathrm{ml}$ \\
Cholesterol standard & -- & $10 \mu \mathrm{l}$ & -- & - & $20 \mu \mathrm{l}$ & -- \\
(2) (conc. 200mg/dl) & & & & & & \\
Specimen & -- & -- & $10 \mu \mathrm{l}$ & -- & -- & $20 \mu \mathrm{l}$ \\
Distilled water & -- & -- & -- & $2.0 \mathrm{ml}$ & $2.0 \mathrm{ml}$ & $2.0 \mathrm{ml}$ \\
\hline
\end{tabular}

Total cholesterol $($ in $\mathrm{mg} / \mathrm{dl})=\left(\right.$ abs. of $\mathrm{T}_{\mathrm{c}} /$ abs. of $\left.\mathrm{S}\right) \mathrm{X} 200$

\section{Estimation of HDL:}

Principle:

Cholesterol $+\mathrm{H}_{2} \mathrm{O}^{\mathrm{CHE}} \longrightarrow$ Cholesterol + free fatty acid

Cholesterol $+\mathrm{O}_{2}{ }^{\mathrm{CHOD}} \longrightarrow$ cholest-4ene 3-one $+\mathrm{H}_{2} \mathrm{O}_{2}$

$\mathrm{H}_{2} \mathrm{O}_{2}+$ Phenol + 4-amino anti pyrine $\stackrel{\mathrm{POD}}{\longrightarrow}$ Quinoneimine complex $+\mathrm{H}_{2} \mathrm{O}$

On addition of precipitating reagent to the serum, followed by centrifugation, HDL fraction remains in the supernatant while the lipoproteins precipitate out.

\section{Procedure:}

Step1: Pipette into the centrifuge tube. (Table 2).

Mix well and allow to stand at RT for $5 \mathrm{~min}$. Centrifuge at $3000 \mathrm{rpm}$ for $10 \mathrm{~min}$ to get a clear supernatant. If supernatant is not clear (high TGL level) dilute the sample 1:1 normal saline and 
multiply the result with 2. Step 2: Pipette into 3 test tubes labeled Blank(B), Standard (S), HDL cholesterol $\left(\mathrm{T}_{\mathrm{H}}\right)$ a shown below(Table 3). Mix well and incubate for $5 \mathrm{~min}$ at $37^{\circ} \mathrm{C}$ or $10 \mathrm{~min}$ at R.T. Read the absorbance of standard(S), HDL cholesterol $\left(\mathrm{T}_{\mathrm{H}}\right)$ against blank at $505 \mathrm{~nm}$ or with green filter(500-540nm)

Table 2: Estimation of HDL:

\begin{tabular}{lr}
\hline Serum / plasma & $0.2 \mathrm{ml}$ \\
Precipitating reagent(3) & $0.3 \mathrm{ml}$ \\
\hline \multicolumn{2}{l}{ Table 3: Estimation of $\mathbf{H D L}:$}
\end{tabular}

\begin{tabular}{lllllll}
\hline Reagent & \multicolumn{3}{l}{$\mathbf{1 . 0 m l}$ procedure } & \multicolumn{3}{c}{$\mathbf{3 . 0}$ ml procedure } \\
& $\mathbf{B}$ & $\mathbf{S}$ & $\mathbf{T}_{\mathbf{H}}$ & $\mathbf{B}$ & $\mathbf{S}$ & $\mathbf{T}_{\mathbf{H}}$ \\
\hline Cholesterol reagent (1) & $1.0 \mathrm{ml}$ & $1.0 \mathrm{ml}$ & $1.0 \mathrm{ml}$ & $1.0 \mathrm{ml}$ & $1.0 \mathrm{ml}$ & $1.0 \mathrm{ml}$ \\
HDL Cholesterol standard & -- & $100 \mu \mathrm{l}$ & -- & - & $200 \mu l$ & -- \\
(4) (conc. 50mg/dl) & & & & & & \\
Supernatant (from step1) & -- & -- & $100 \mu l$ & -- & -- & $200 \mu l$ \\
Distilled water & $100 \mu \mathrm{l}$ & -- & -- & $2.2 \mathrm{ml}$ & $2.0 \mathrm{ml}$ & $2.0 \mathrm{ml}$ \\
\hline
\end{tabular}

\section{Calculations:}

HDL cholesterol $($ in $\mathrm{mg} / \mathrm{dl})=\left(\right.$ abs. of $\mathrm{T}_{\mathrm{H}} /$ abd. of S) X 50 (clin, Chem 20,470. (Allain, C.C. et al., 1974)).

\section{Tissue Biochemical Methods:}

\section{Preparation of homogenate:}

The animals were sacrificed and liver isolated and weighed, the homogenate is prepared as follows.

\section{Reagent:}

1.0.25 M sucrose solution: $85.87 \mathrm{gm}$ of sucrose was dissolved in $1000 \mathrm{ml}$ of distilled water. 2.10 $\mathrm{mM}$ buffer solution: $1.2 \mathrm{gm}$ of tris was dissolved in $900 \mathrm{ml}$ of distilled water, $\mathrm{pH}$ was adjusted to 7.4 with $1 \mathrm{M} \mathrm{Hcl} \&$ dilute up to $1000 \mathrm{ml}$.

\section{Procedure:}

Liver was separated and kept in cold condition were cross chopped with surgical scalpel in to fine slices and was chilled in the cold $0.25 \mathrm{M}$ sucrose, quickly blotted with filter paper. The tissue was minced and homogenized in ice cold $10 \mathrm{mM}$ tris $\mathrm{HCL}$ buffer (to $\mathrm{pH} 7.4$ ) at a concentration of $10 \%(\mathrm{w} / \mathrm{v})$ with 25 strokes of tight Teflon pestle of glass homogenizer at a speed of $2500 \mathrm{rpm}$. The prolonged homogenization under hypotonic condition was designed to disrupt as far as possible the ventricular structure of cells so as to release soluble protein and leave only membrane and non vascular matter in a sediment able form It was then centrifuged in cooling centrifuge at 5000 RPM for $20{ }^{0} \mathrm{C}$, temperature was maintained at $-4{ }^{0} \mathrm{C}$ during the 
centrifugation, clear supernatant was separated and used to estimate SOD, Catalase, Glutathione, MDA.

\section{Evaluation of Antioxidant status:}

\section{Super oxide dismutase (SOD)}

2. Catalase:

3. Reduced Glutathione (GSH

4. Evaluation of Pro-oxidant

\section{Super oxide dismutase (SOD)}

SOD was estimated by the method of Misra and Fridovich (1972)

\section{Principle:}

Rate of auto oxidation of epinephrine \& the sensitivity of this auto oxidation to inhibition by SOD were augmented as ph was raised from 7.8-10.2, $\mathrm{O} 2$ generated by xanthine oxidase reaction, caused by the oxidation of epinephrine to adrenochrome \& the yield of adrenochrome produced per $\mathrm{O} 2$ introduced. the auto oxidation of epinephrine proceeds by at least two distinct pathways only one of which is free radical chain reaction involving O2\&hence inhabitable by SOD.

\section{Procedure:}

$0.5 \mathrm{ml}$ of sample was diluted with diluted with $0.5 \mathrm{ml}$ of distilled water, to this $0.25 \mathrm{ml}$ ethanol, $0.5 \mathrm{ml}$ of chloroform (all reagents chilled) was added the mixture was shaken for 1 min\& centrifuged at $2000 \mathrm{rpm}$ for $20 \mathrm{~min}$. The enzymatic activity in supernatant was determined. To $0.05 \mathrm{ml}$ of carbonate buffer $(0.05 \mathrm{M}, \mathrm{pH} 10.2) \& 0.5 \mathrm{ml}$ of EDTA $(0.49 \mathrm{M})$ was added. The reaction was initiated by the addition of $0.4 \mathrm{ml}$ of epinephrine $\&$ the change in optical density/min was measured at 480nm. SOD activity was expressed as units / mg protein change in optical density / min. $50 \%$ inhibition of epinephrine to adrenochrome transition by enzyme is taken the enzyme unit. Calibration curve was prepared by using 10 -125 units of SOD.

\section{Formula:}

SOD $=$
$\mathrm{Y}=$ Final reading - Initial reading.

\section{Catalase:}

Catalase was estimated by Hugo E. Aebi method: Hydrogen peroxide: hydrogenperoxidoreduatase In U.V range $\mathrm{H}_{2} \mathrm{O}_{2}$ can be followed directly by the decrease in absorbance (O.D 240) per unit time is a measure of catalase activity.

$\mathrm{H}_{2} \mathrm{O}_{2} \quad \rightarrow \quad \mathrm{H}_{2}+\mathrm{O}_{2}$




\section{$\mathrm{RDOH} \quad \rightarrow \quad \mathrm{H}_{2} \mathrm{O}+\mathrm{ROH}+\mathrm{A}$}

Decomposition of $\mathrm{H}_{2} \mathrm{O}_{2}=$ Decrease in absorbance at $240 \mathrm{~nm}$

\section{Procedure:}

Dilute homogenate 20 times with Phosphate buffer pH 7.0

Blank

1. $4 \mathrm{ml}$ homogenate diluted

2. $2 \mathrm{ml}$ Phosphate buffer $\mathrm{pH} 7.0$

3.

\section{Calculation}

$\log A / B \times 2297.3$ where

- A: Initial absorbance

○ B: final absorbance (after 30 second)

○ Units $=\mu$ moles of $\mathrm{H}_{2} \mathrm{O}_{2}$ consumed $/ \mathrm{min} / \mathrm{mg}$
Test

1. $2 \mathrm{ml}$ homogenate diluted

2.

3. $1 \mathrm{ml} \mathrm{H} \mathrm{H}_{2}$ (8.5 micro lit. in $2.5 \mathrm{ml}$ phosphate buffer ;( 50mM/l; pH 7.0).

\section{Reduced Glutathione (GSH)}

Reduced Glutathione was determined by the method of (Moran et al.,2008)

\section{Procedure:}

To $1 \mathrm{ml}$ of sample $1 \mathrm{ml}$ of $10 \%$ TCA was added. The precipitated fraction was centrifuged and to $0.5 \mathrm{ml}$ supernatant, $2 \mathrm{ml}$ of DTNB reagent was added. The final volume was made up to $3 \mathrm{ml}$ with phosphate buffer. The colour developed was read at $412 \mathrm{~nm}$. The amount of glutathione was expressed as $\mu \mathrm{g}$ of $\mathrm{GSH} / \mathrm{mg}$ protein reduced glutathione was used as standard $(100 \mu \mathrm{g} / \mathrm{ml})$.

\section{Calculation:}

$$
\mathrm{X}=(\mathrm{Y}-0.0046) / 0.0034
$$

\section{Where $\mathbf{Y}=$ Absorbance of test sample.}

\section{Evaluation of Pro-oxidant}

Lipid peroxidation (Malondialdehyde formation) Malondialdehyde formation was estimated by the method of (Slater and sawyer et al., 1971)

\section{Procedure:}

$2 \mathrm{ml}$ of sample was mixed with $2 \mathrm{ml}$ of $20 \%$ trichloroacetic acid and kept in ice for $15 \mathrm{~min}$. The precipitate was separated by centrifugation and $2 \mathrm{ml}$ of samples of clear supernatant solution were mixed with $2 \mathrm{ml}$ of aq. 0.67 thiobarbituric acid. This mixture was then heated on a boiling water bath fir $10 \mathrm{~min}$. It was then cooled in ice for $5 \mathrm{~min}$ and absorbance was read at $535 \mathrm{~nm}$. The values expressed as $\mathrm{nm}$ of MDA formed/mg of protein. Values are normalized to protein content of tissue. 


\section{Calculation:}

$$
\mathrm{X}=(\mathrm{Y}+0.002) / 0.0026086)
$$

Where $\mathrm{Y}=$ Absorbance difference of final (after $3 \mathrm{~min}$.) \& initial reading of test sample

\section{Physical methods:}

\section{Body weight:}

The animals weight were taken on day 1 and then animals weights were again taken on day 45 and compared the difference between the day 1 and day 45 .

\section{Histopathology}

Liver and carotid artery were collected after the rats were sacrificed in $10 \%$ formal saline solution and utilized for the histopathological studies. Liver and carotid artery were separated from Normal, high fat diet treated, and Alpha-linolenic acid thigh fat diet treated and Atrovastatin +high fat diet treated groups after rats were sacrified and blotted free of blood and tissue fluids. They are fixed in bovin`s fluid (picric acid: Formalin: Acetic acid in the ratio of 75 $: 52$ : 5. After 24 hours the tissue were washed thoroughly in $70 \%$ alcohol and then de hydrated in ascending grades of alcohol (70,100\%). Dehydration in absolute alcohol was followed by treatment of tissue with toluene-xylin ( 50:50) followed by $10 \%, 50 \%, 70 \%, 90 \%$ paraffin wax in toluene and finally to changes in $100 \%$ paraffin wax,60-62 C followed by embedding of tissue in wax.

5-15 micro-meter thick section were serially cut in leitz microtome in horizontal plane and mounted in glass slide with the help of egg albumin in glycerin solution $(50 \% \mathrm{v} / \mathrm{v})$. The section were deparaffinated in xylin and downgraded through 100, 90, 50 and 30\% alcohol and then finally in water. They were then stained with 105 hematoxylin for 3-5 minutes and staining was intensified by running water. The hematoxylin stained section was stained with $10 \%$ eosin for two minutes and were then quickly passes through ascending grades of alcohol and finally treated with xylin followed by mounting in DPX. The sections were observed and desired area was photographed in a Olympus microscope. The sections were observed under 40X magnifications.

\section{Statistical analysis}

All the data expressed as mean \pm SEM. Statistical significance between more than two groups was tested using one way ANOVA followed by the Tukey test using computer based fitting program (Prism, Graph pad.). Statistical significant was determined at $\mathrm{P}<0.05$ (Armin Graber et al., 2011). 


\section{RESULTS AND DISCUSSION}

\section{Results of Serum analytical parameters:}

\section{Cholesterol}

Administration of high fat diet and cholesterol in rats show significant $(\mathrm{P}<0.001)$ increase in the cholesterol levels in blood serum compared to respective Normal group. Treatment with Alpha-linolenic acid and Atrovastatin show significant $(\mathrm{P}<0.001)$ reduction in the amount of cholesterol in Alpha-linolenic acid + high fat diet treated group and atrovastatin + high fat diet group compared to respective high fat diet group. Cholesterol levels in blood serum of all groups Normal, high fat diet treated group, Alpha-linolenic acid + high fat diet administered group and Atrovastatin + high fat treated group(Table 4).

Table 4:Cholesterol:

\begin{tabular}{ll}
\hline Groups & $\begin{array}{l}\text { Values } \\
\text { (cholesterol mg/dl) }\end{array}$ \\
\hline Normal & $133.6 \pm 24.06 * * *$ \\
High fat diet treated group & $521.6 \pm 13.9$ \\
$\begin{array}{l}\text { Alpha-linolenic acid + high } \\
\text { fat diet treated group }\end{array}$ & $101.8 \pm 5.951 * * *$ \\
$\begin{array}{l}\text { Atrovastatin + high fat } \\
\text { treated group. }\end{array}$ & $132.8 \pm 18.55 * * *$ \\
\hline
\end{tabular}

All values shown are mean \pm SEM and $n=6$.

$* * * \mathrm{P}<0.001$ Compared to high fat diet treated group.

Effect of Alpha-linolenic acid on Total Cholesterol levels of all groups Normal, high fat diet, high fat diet+ Alpha-linolenic acid, and high fat diet + atrovastatin. groups.

All values shown are mean \pm SEM and $n=6$.

$* * * \mathrm{P}<0.001$ Compared to group.

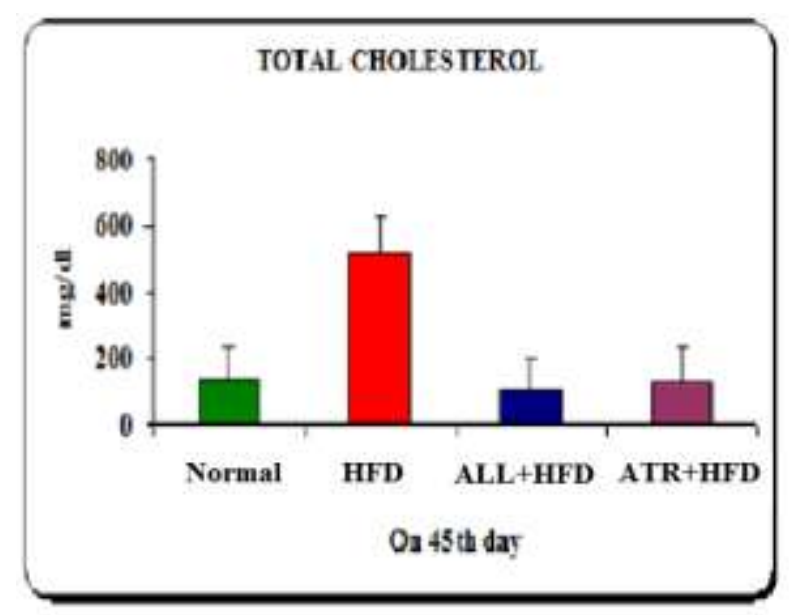

Figure 1: Cholesterol 


\section{HDL cholesterol:}

There was a significant $(\mathrm{P}<0.001)$ decrease in the HDL cholesterol levels in blood serum of high fat diet treated group compared to Normal group. There was a significant $(\mathrm{P}<0.001)$ increase in the amount of HDL cholesterol levels in Alpha-linolenic acid + high fat diet treated group and atrovastatin + high fat diet treated groups compared to respective high fat diet treated group. HDL cholesterol in blood serum of all groups Normal, high fat diet treated group, Alphalinolenic acid + high fat diet administered group and Atrovastatin + high fat treated group(Table 5).

All values shown are mean \pm SEM and $n=6$.

$* * * \mathrm{P}<0.001$ Compared to high fat diet treated group.

Effect of Alpha-linolenic acid on HDL Cholesterol levels of all groups Normal, high fat diet, high fat diet+ Alpha-linolenic acid, and high fat diet + atrovastatin. groups

All values shown are mean \pm SEM and $n=6$.

$* * \mathrm{P}<0.001$ Compared high fat diet group

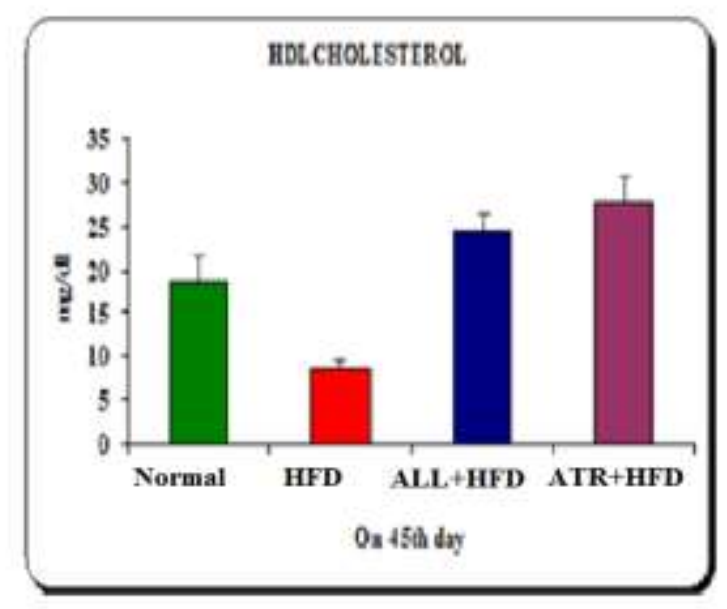

Figure 2: HDL Cholesterol

Table 5 HDL cholesterol

\begin{tabular}{ll}
\hline Groups & Values(HDL Cholesterol mg/dl) \\
\hline Normal & $18.59 \pm 3.037 * * *$ \\
High fat diet treated group & $8.547 \pm 0.934$ \\
Alpha-linoleic acid + high fat diet treated & $24.47 \pm 1.879 * * *$ \\
group & \\
Atrovastatin+ high fat treated group. & $27.76 \pm 2.86 * * *$ \\
\hline
\end{tabular}

All values shown are mean \pm SEM and $n=6$.

$* * * \mathrm{P}<0.001$ Compared to high fat diet treated group. 


\section{Total protein}

There was a significant $(\mathrm{P}<0.002)$ increase in the Total Protein levels in blood serum of high fat diet treated group compared to Normal group. There was a significant $(\mathrm{P}<0.002)$ decrease in the amount of Total Protein levels in Alpha-linolenic acid + high fat diet treated group and atrovastatin + high fat diet treated groups compared to respective high fat diet treated group.

Total protein levels in blood serum of all groups Normal, high fat diet treated group, Alphalinolenic acid + high fat diet administered group and Atrovastatin + high fat treated group(Table $6)$.

The oxidative stress was measured in rat liver homogenate on $45^{\text {th }}$ day in Normal, high fat diet treated group, Alpha-linolenic acid $(0.2 \%)+$ high fat diet administered group and Atrovastatin $(0.5 \mathrm{mg})+$ high fat treated group.

Effect of Alpha-linolenic acid on Total protein levels of all groups Normal, high fat diet, high fat diet + Alpha-linolenic acid, and high fat diet+ atrovastatin groups. All values shown are mean \pm SEM and $n=6$.

Table 6: Total protein

\begin{tabular}{ll}
\hline Groups & Values( Total protein) \\
\hline Normal & $10.20 \pm 1.363 * * *$ \\
High fat diet treated group & $17.54 \pm 1.633$ \\
Alpha-linolenic acid + high fat diet treated group & $9.070 \pm 0.7082 * * *$ \\
Atrovastatin+ high fat treated group. & $2.216 \pm 0.9048 * * *$ \\
\hline
\end{tabular}

All values shown are mean \pm SEM and $n=6$.

$* * * \mathrm{P}<0.002$ Compared to high fat diet treated group.

$* * * \mathrm{P}<0.002$ Compared to High fat diet group.

Anti hyper lipidemic activity of Alpha-linolenic acid in high fat diet induced rats:

Results of Tissue (liver) parameters:

There was a significant $(\mathrm{P}<0.01)$ decrease in the in the SOD levels in high fat diet treated group compared to respective Normal group. There was a significant $(\mathrm{P}<0.01),(\mathrm{P}<0.01)$ increase in SOD levels in Alpha-linolenic acid (0.2\%) + high fat diet administered group and Atrovastatin $(0.05 \mathrm{mg})+$ high fat treated groups compared to respective high fat diet treated group.

\section{Superoxide dismutase:}

SOD levels in liver of all groups Normal, high fat diet treated group, Alpha-linolenic acid (0.2\%) + high fat diet administered group and Atrovastatin $(0.05 \mathrm{mg})+$ high fat treated group(Table 7$)$. 


\section{Table 7: Superoxide Dismutase}

\begin{tabular}{ll}
\hline Groups & Values (Units/gram tissue ) \\
\hline Normal & $20.74 \pm 5.863 * * *$ \\
high fat diet treated group & $3.992 \pm 1.835$ \\
Alpha-linoleic acid + high fat diet treated group & $16.29 \pm 2.697 * *$ \\
Atrovastatin + high fat treated group & $16.58 \pm 3.106 * *$ \\
\hline
\end{tabular}

All values shown are mean \pm SEM and $n=6$.

$* * \mathrm{P}<0.01, * * * \mathrm{P}<0.001$ Compared to high fat diet treated group .

Effect of Alpha-linolenic acid on SOD levels of all groups Normal, high fat diet, high fat diet+ Alpha-linolenic acid, and High fat diet +atrovastatin. groups.

All values shown are mean \pm SEM and $n=6$.

$* * \mathrm{P}<0.01, * * * \mathrm{P}<0.001$ to high fat diet group.

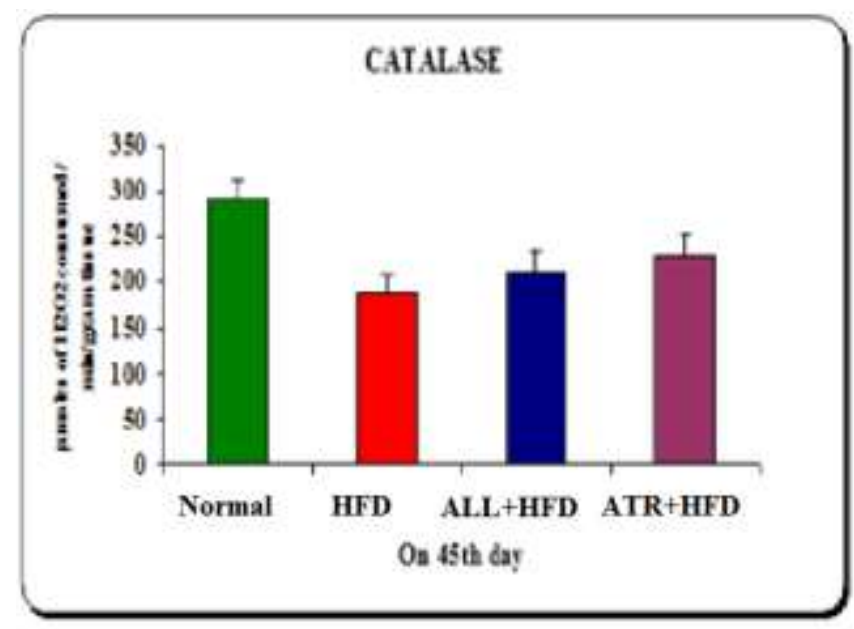

Figure 3: Superoxide Dismutase

\section{Catalase:}

There was a significant $(\mathrm{P}<0.001)$ decrease in the catalase levels in high fat diet treated compared to respective Normal group. There was significant increase $(\mathrm{P}<0.01)$ in catalase levels in Alpha-linolenic acid $(0.2 \%)+$ high fat diet administered group and Atrovastatin $(0.05 \mathrm{mg})+$ high fat treated groups compared to respective high fat diet treated group.

Catalase levels in liver of all groups Normal, high fat diet treated group, Alpha-linolenic acid $(0.2 \%)+$ high fat diet administered group and Atrovastatin $(0.05 \mathrm{mg})+$ high fat treated group(Table 8).

Table 8: Catalase

\begin{tabular}{ll}
\hline Groups & $\begin{array}{l}\text { Values }\left(\mu \text { moles of } \mathrm{H}_{2} \mathrm{O}_{2}\right. \\
\text { consumed/ min/gram tissue })\end{array}$ \\
\hline Normal & $292.51 \pm 3.6 * * *$ \\
\hline
\end{tabular}


high fat diet treated group $\quad 188.21 \pm 2.4$

Alpha-linolenic acid + high fat diet treated group $213.26 \pm 2.45 * *$

Atrovastatin+ high fat treated group.

$229.56 \pm 3.65 * * *$

All values shown are mean \pm SEM and $n=6$.

$* * \mathrm{P}<0.01, * * * \mathrm{P}<0.001$ Compared to high fat diet treated.

Effect of Alpha-linolenic acid on CATALASE levels of all groups Normal, high fat diet, high fat diet+ Alpha-linolenic acid , and high fat diet +atrovastatin. Groups.

All values shown are mean \pm SEM and $n=6$.

$* * \mathrm{P}<0.01, * * * \mathrm{P}<0.001$ Compared to high fat diet group

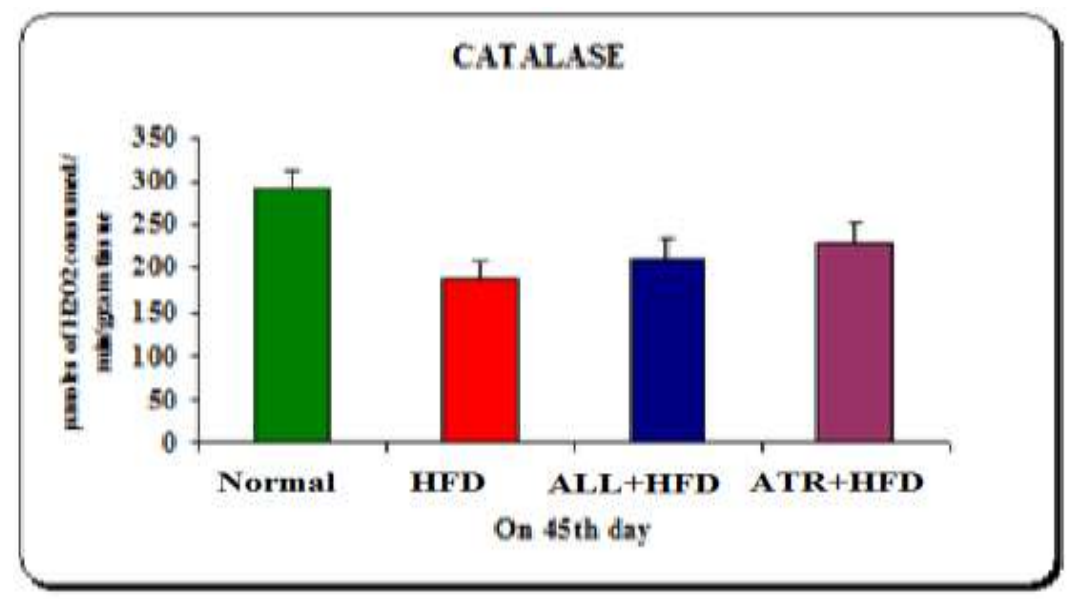

Figure 4: Catalase

\section{Glutathione:}

There was a significant decrease $(\mathrm{P}<0.01)$ in the GSH levels in high fat diet group compared to respective Normal group. There was a significant increase $(\mathrm{P}<0.01)(\mathrm{P}<0.001)$ in GSH levels in Alpha-linolenic acid $(0.2 \%)+$ high fat diet administered group and Atrovastatin $(0.05 \mathrm{mg})+$ high fat treated groups compared to respective high fat diet treated group.

Glutathione levels in liver of all groups Normal, high fat diet treated group, Alpha-linolenic acid $(0.2 \%)+$ high fat diet administered group and Atrovastatin $(0.05 \mathrm{mg})+$ high fat treated group(Table 9).

\section{Table 9:Glutathione}

\begin{tabular}{ll}
\hline Groups & Values $(\boldsymbol{\mu g}$ of GSH / g tissue) \\
\hline Normal & $112.6 \pm 10.07 * * *$ \\
high fat diet treated group & $75.37 \pm 5.092$ \\
Alpha-linolenic acid + high fat diet & $99.55 \pm 10.09 * *$ \\
treated group & \\
Atrovastatin+ high fat treated group. & $106.6 \pm 9.134 * * *$ \\
\hline
\end{tabular}

All values shown are mean \pm SEM and $n=6$.

$* * \mathrm{P}<0.01, * * * \mathrm{P}<0.001$ Compared to high fate diet treated. 


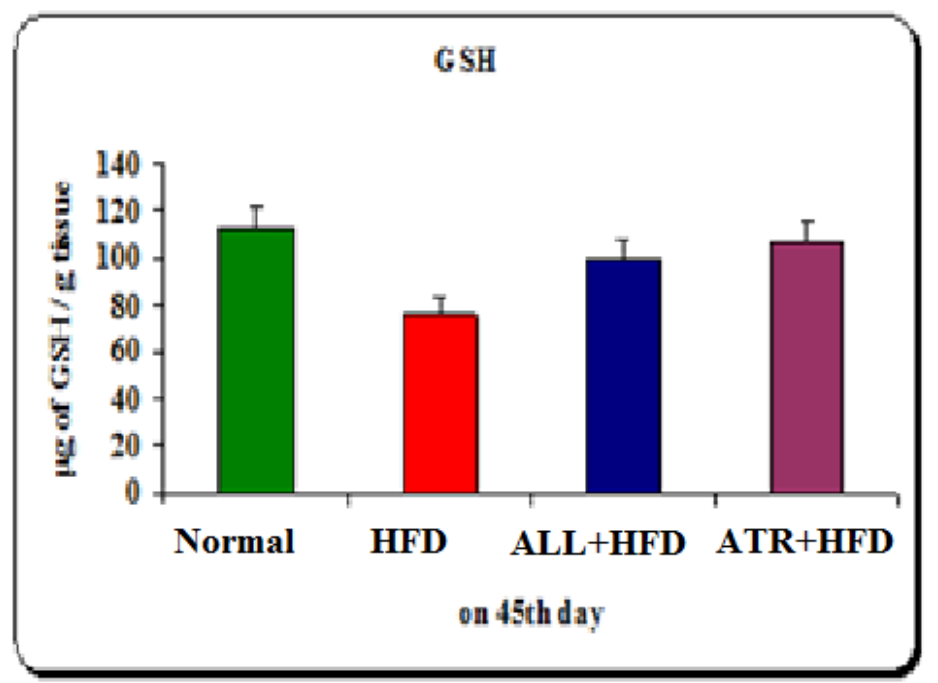

Figure 5 Glutathione

Effect of Alpha-linolenic acid on GLUTATHIONE levels of all groups Normal, high fat diet, high fat diet + Alpha-linolenic acid , and high fat diet +atrovastatin. groups.

All values shown are mean \pm SEM and $n=6$.

$* * \mathrm{P}<0.01, * * * \mathrm{P}<0.001$ Compared to high fat diet group.

\section{Malondialdehyde:}

There was a significant increase $(\mathrm{P}<0.001)$ in the MDA levels in high fat diet group compared to respective Normal group. There was a significant $(\mathrm{P}<0.05),(\mathrm{P}<0.01)$ decrease in MDA levels in Alpha-linolenic acid (0.2\%) + high fat diet administered group and Atrovastatin $(0.05 \mathrm{mg})+$ high fat treated groups compared to respective high fat diet treated group.

Malondialdehyde levels in liver of all groups Normal, high fat diet treated group, Alpha-linolenic acid $(0.2 \%)+$ high fat diet administered group and Atrovastatin $(0.05 \mathrm{mg})+$ high fat treated group(Table 10).

Table 10: Malondialdehyde

\begin{tabular}{ll}
\hline Groups & Values (nm of MDA / g tissue) \\
\hline Normal & $1.937 \pm 0.2214 * * *$ \\
High fat diet treated group & $3.421 \pm 0.2786$ \\
Alpha-linolenic acid + high fat diet treated group & $1.821 \pm 0.22 * * *$ \\
Atrovastatin+ high fat treated group. & $1.327 \pm 0.2048 * * *$ \\
\hline
\end{tabular}

All values shown are mean \pm SEM and $n=6$.

$* * \mathrm{P}<0.001$ Compared to high fate diet treated

Effect of Alpha-linolenic acid on MDA levels of all groups Normal, high fat diet, high fat diet+ Alpha-linolenic acid, and high fat diet +atrovastatin. groups. 
All values shown are mean \pm SEM and $n=6$.

$* * * \mathrm{P}<0.001$ Compared to high fat diet group.

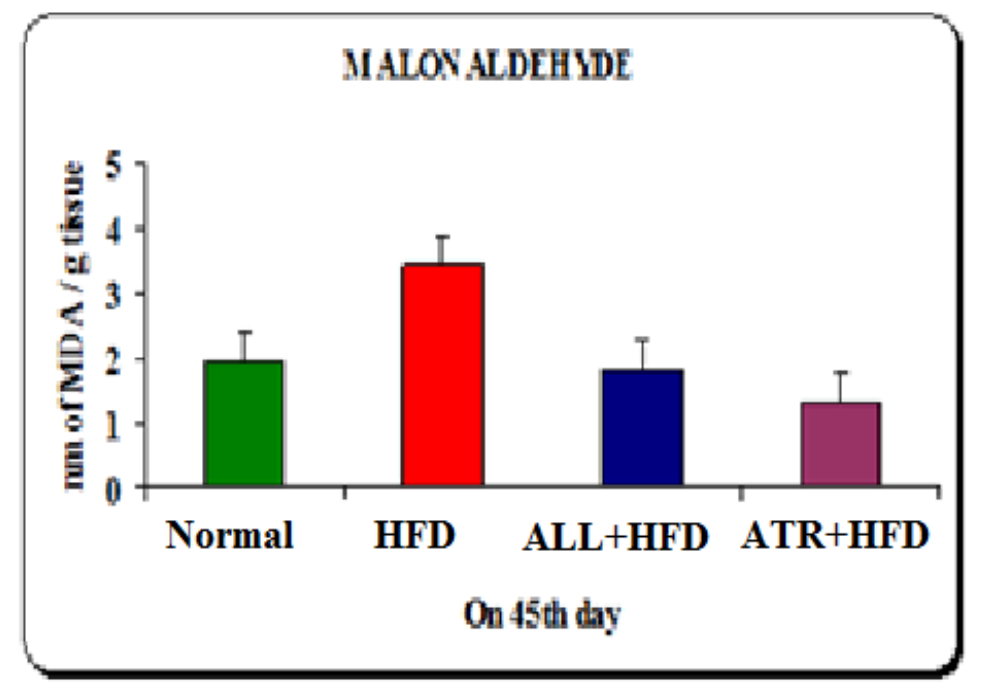

Figure 6: Malondialdehyde

\section{Body weight:}

Body weight of all groups Normal, high fat diet treated group, Alpha-linolenic acid + high fat diet administered group and Atrovastatin + high fat treated group on day 1.(table 8) Administration of high fat diet and cholesterol in rats show significant $(\mathrm{P}<0.001)$ increase in bodyweight in high fat diet treated group compared to respective Normal group. There was a significant $(\mathrm{P}<0.001)$ decrease in body weight in Alpha-linolenic acid + high fat diet treated group and atrovastatin +high fat diet treated groups compared to respective high fat diet treated group after 45 days(Table 11).

Table 11: Bodyweight

\begin{tabular}{lll}
\hline Groups & \multicolumn{2}{l}{ Body weight in grams } \\
& on day 1 & On day 45 \\
\hline Normal & $100.8 \pm 5.23$ & $120.7 \pm 5.74 * * *$ \\
High fat diet treated group & $98.3 \pm 8.207$ & $171.7 \pm 6.009$ \\
$\begin{array}{l}\text { Alpha-linolenic acid }+ \text { high fat diet } \\
\text { treated group }\end{array}$ & $112.3 \pm 4.041$ & $145.0 \pm 4.28 * * *$ \\
Atrovastatin+ high fat treated group & $113.3 \pm 10.54$ & $143.0 \pm 6.66 * * *$ \\
\hline
\end{tabular}



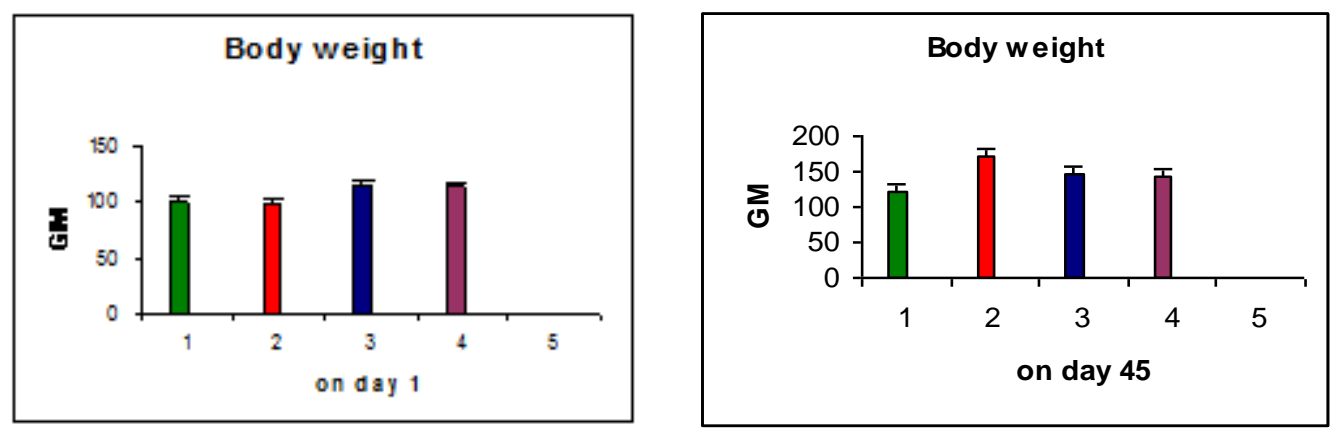

Figure 7: Body weight

Effect of Alpha-linolenic acid on body weight levels of all groups Normal, high fat diet, high fat diet+ Alpha-linolenic acid , and high fat diet +atrovastatin. groups.

All values shown are mean \pm SEM and $\mathrm{n}=6$.

$* * * \mathrm{P}<0.0001$ Compared to high fat diet group.

\section{Histopathological findings:}

\section{Liver}

On histological examination of liver section of high fat diet groups showed fat deposition in majority of cells accompanied by white globules formation, extensive intercellular hemorrhage. These histological observations support the presence of cholesterol deposition. On administration of Alpha-linolenic acid and atrovastatin treated groups significantly decrease the cholesterol formation are observed all most similar like normal liver section.

\section{Carotid artery}

In examination of carotid artery of high fat diet groups showed fat deposition in the artery and it shows presence of fatty patches and may be thrombus formation, and congestion of blood vessels. These histological observations support that the deposition of cholesterol. On administration of Alpha-linolenic acid and atrovastatin treated groups significantly decrease the cholesterol deposition observed all most similar like normal carotid artery.

PHOTO MICRO GRAPHS OF LIVERS:

Histopathology: 


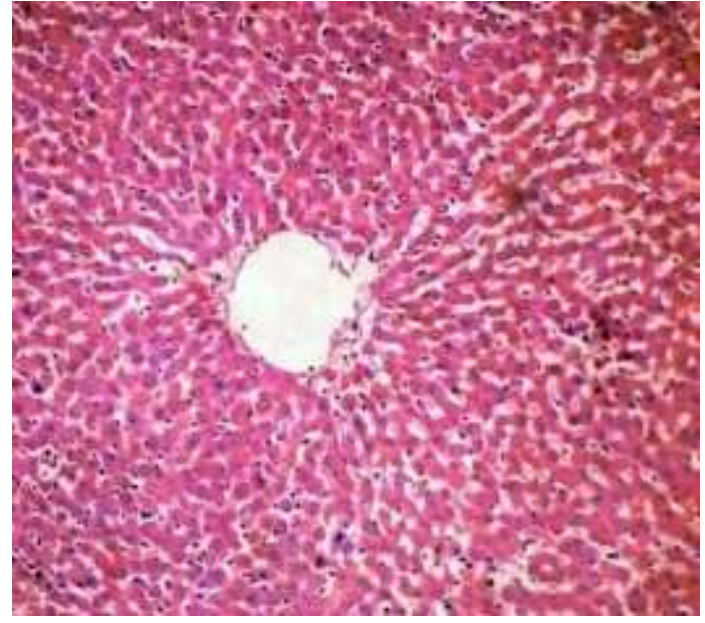

Figure 8:Normal liver

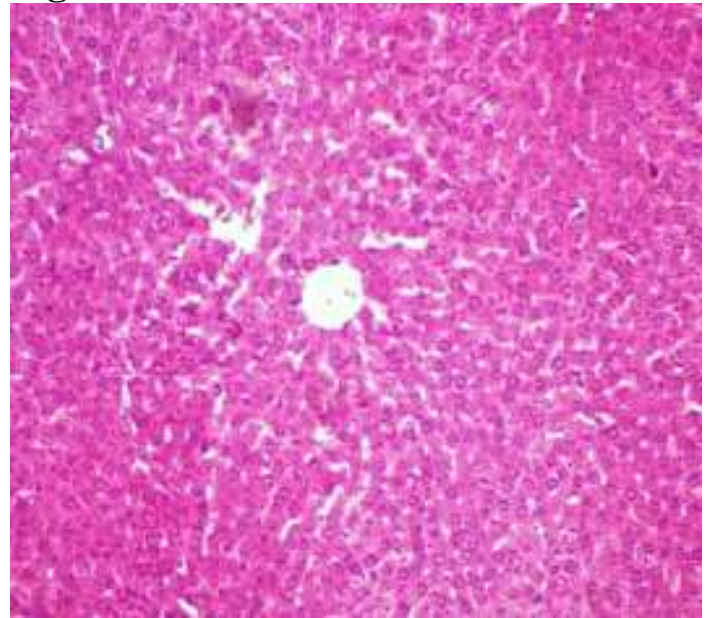

Figure 10: Alpha-linolenic acid +HFD HFD = High Fat Diet

PHOTO MICRO GRAPHS OF CAROTID ARTERY:

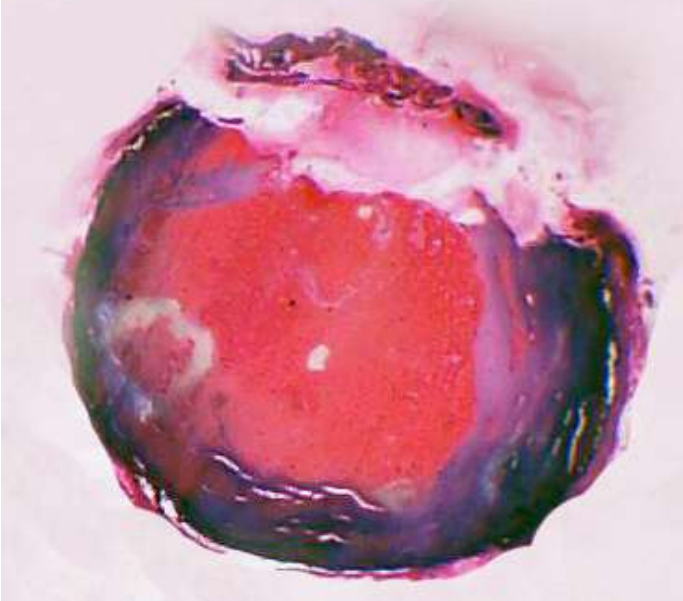

Figure 12:Normal Carotid artery

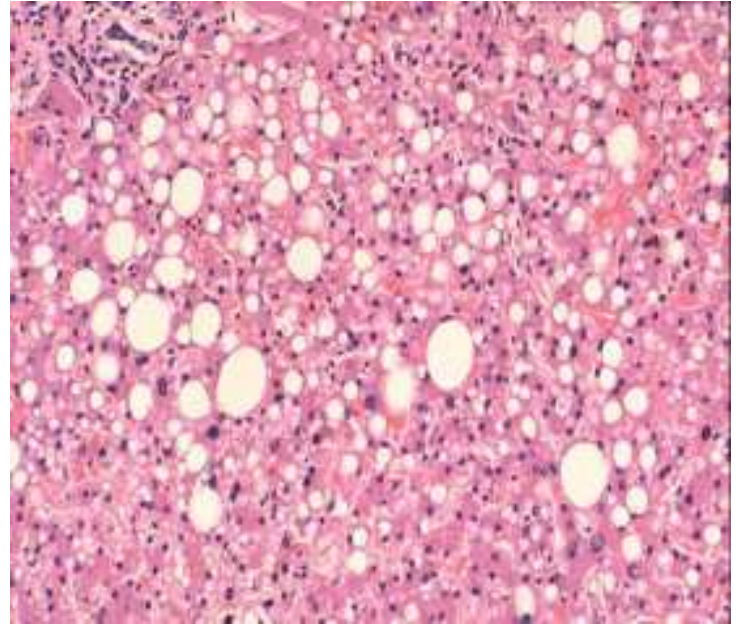

Figure 9: HFD induced

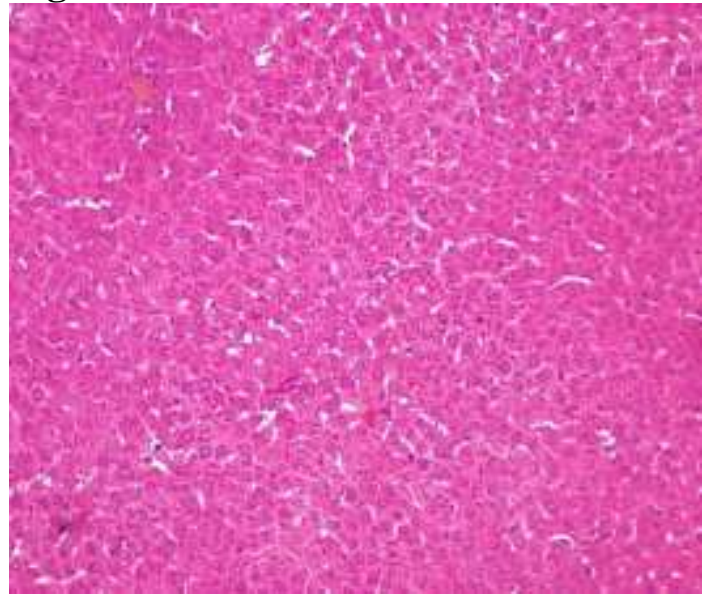

Figure 11: Atrovastatin +HFD

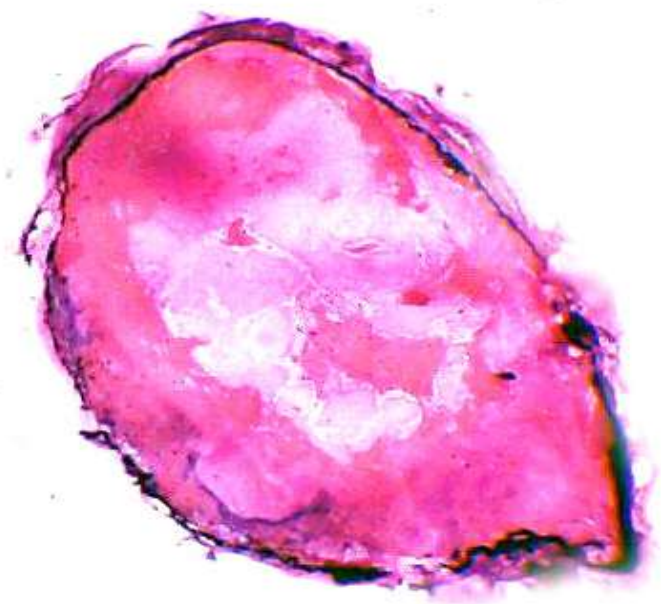

Figure 13: HFD induced 


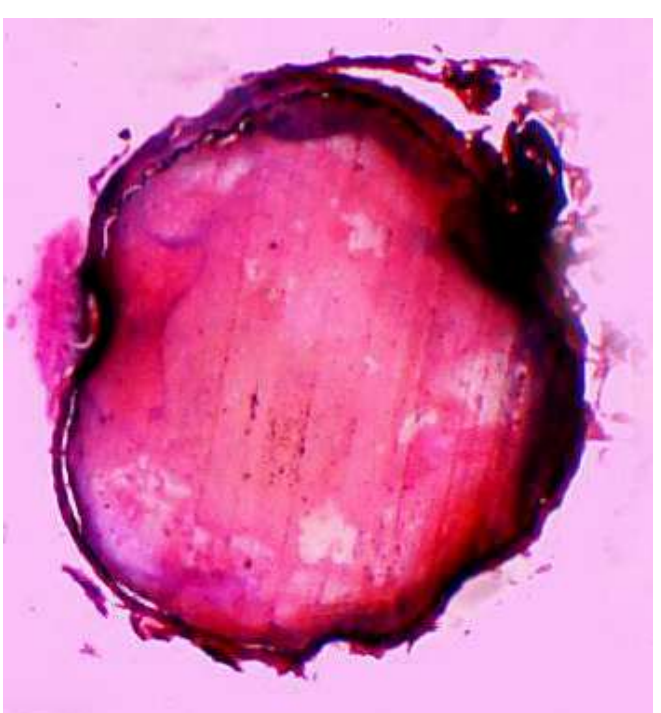

Figure 14: Alpha-linolenic acid + HFD

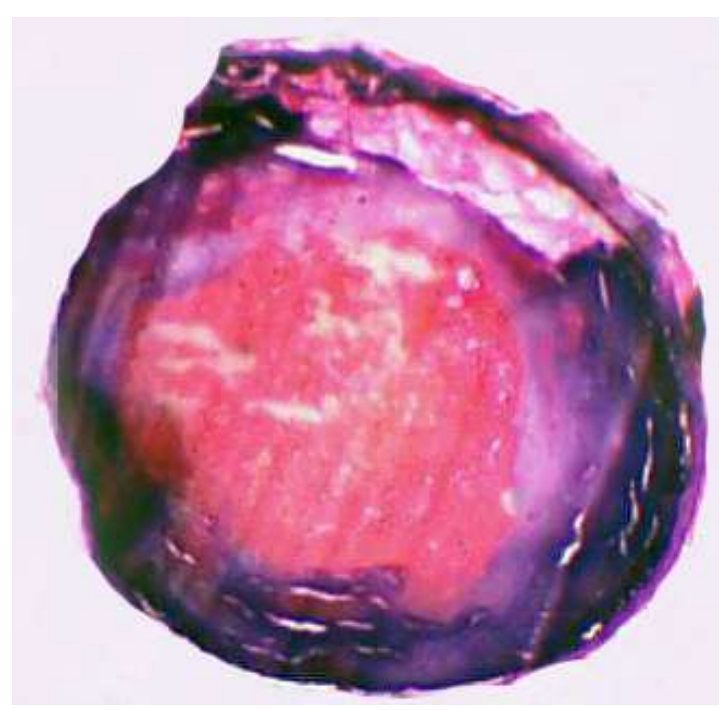

Figure 15: Atrovastatin +HFD

\section{DISCUSSION:}

Hyperlipidemia has plagued humans from antiquity and constitutes a major health problem. Despite dramatic progress in both medical and surgical areas, still management of Hyperlipidemia is not complete. The goal of the medical treatment is the prevention of Hyperlipidemia with synthetic drugs, Each suffers from their own disadvantages, still offering a wide scope of research in this particular area. Many research laboratories are pursuing investigations in Anti Hyperlipidemia in both the preclinical and clinical areas. Various factors involved in fat deposition are still being recognized and evaluated. The aim of the present study is also an attempt in this direction.

Despite considerable effort on the part of a number of investigators, there has been only a limited success in developing an ideal animal model of lipidemic disease that faithfully mimics human Hyperlipidemia. Various procedures have been reported by numerous investigators from time to time such as selective diets, High fat diets, drug induced Hyperlipidemia in experimental animals.

In the animal model, Hyperlipidemia induces not only fat deposition damage to the cells of organs that leads generation of free radicals.

The experimental model selected for the present study is administration High fat diet every day and cholesterol $(0.5 \%)$ orally at every alternative day.

The present study on Hyperlipidemia and oxidative stress was carried out on the female albino rats of Wister strain. The project was aimed to study the Anti hyperlipidemia and oxidative stress and protective role of Alpha-linolenic acid in hyperlipidemia. Bio-chemical parameters of 
hyperlipidemia and oxidative stress were analyzed from liver homogenate and serum. Histopathological study was carried out to confirm the biological changes.

In the present study, administration of High fat diet to rats caused significant increase in oxidative stress i.e. decreased activity of SOD, Catalase and decreased levels of GSH while increased levels of LPO. Administration of High fat diet to rats also increased deposition of fat in liver and various blood vessels.

\section{CONCLUSION:}

All synthetic drugs like fibrates and statins have their won adverse effects .for example atrovastatin have constipation, sleep disturbances, abnormal liver function values. And rhabdomyolysis with acute renal failure and it has fallowing drug interactions. Drugs like erythromycin, azole antifungals, cyclosporine, or niacin that interfere with metabolism or its protein binding may increase serum concentration of atrovastatin and risk of myopathy. To over from these problems we use natural synthetic drugs like Alpha-linolenic acid .

The present study finds out the role of anti-hyperlipidemic and antioxidant activity of Alphalinolenic acid in hyperlipidemia.

From the present study the following conclusions can be made: Administration of high fat diet + cholesterol $(0.5 \%)$ increase in fat formation and fat deposition in liver and carotid artery. It also increases the levels of biomarkers of oxidative stress in the liver. The increase in serum cholesterol and total protein in high fat diet + cholesterol $(0.5 \%)$ group rats were also observed.

In conclusion, the study seemed to reveal that high fat and high anti-oxidant nutrition play the aggregative and alleviative roles respectively in the context of lipid and oxidative stress status as high fat diet feeding for 45 days resulted in raising both lipid and oxidative stress status in blood and hepatic tissues. However these effects were considerable lowered by high all antioxidants diets each when fed in combination with high fat diet.

\section{REFERENCE:}

1. Akinkuolie AO, Ngwa JS, Meigs JB, et al. Omega-3 polyunsaturated fatty acid and insulin sensitivity: a meta-analysis of randomized controlled trials. Clin Nutr (Edinburgh, Scotland) 2011;30:702-7.

2. Egert S, Fobker M, Andersen G, et al. Effects of dietary alpha-linolenic acid, eicosapentaenoic acid or docosahexaenoic acid on parameters of glucose metabolism in healthy volunteers. Ann Nutr Metab 2008;53:182-7. 
3. Wendland E, Farmer A, Glasziou P, et al. Effect of alpha linolenic acid on cardiovascular risk markers: a systematic review. Heart (British Cardiac Society) 2006;92:166-9.

4. Barre DE. The role of consumption of alpha-linolenic, eicosapentaenoic and docosahexaenoic acids in human metabolic syndrome and type 2 diabetes - a minireview. J Oleo Sci 2007;56:319-25.

5. Hartweg J, Perera R, Montori V, et al. Omega-3 polyunsaturated fatty acids (PUFA) for type 2 diabetes mellitus. Cochrane Database Syst Rev 2008. Cd003205doi: 10.1002/14651858.CD003205.pub2.

6. Ma Y, Njike VY, Millet J, et al. Effects of walnut consumption on endothelial function in type 2 diabetic subjects: a randomized controlled crossover trial. Diabetes Care 2010;33:227-32.

7. Tapsell LC, Gillen LJ, Patch CS, et al. Including walnuts in a low-fat/modified-fat diet improves HDL cholesterol-to-total cholesterol ratios in patients with type 2 diabetes. Diabetes Care 2004;27:2777-83.

8. Taylor CG, Noto AD, Stringer DM, et al. Dietary milled flaxseed and flaxseed oil improve N-3 fatty acid status and do not affect glycemic control in individuals with wellcontrolled type 2 diabetes. J Am Coll Nutr 2010;29:72-80.

9. McManus RM, Jumpson J, Finegood DT, et al. A comparison of the effects of n-3 fatty acids from linseed oil and fish oil in well-controlled type II diabetes. Diabetes Care 1996;19:463-7.

10. Tapsell LC, Batterham MJ, Teuss G, et al. Long-term effects of increased dietary polyunsaturated fat from walnuts on metabolic parameters in type II diabetes. Eur J Clin Nutr 2009;63:1008-15. 